\title{
The subtropical nutrient spiral
}

\author{
William J. Jenkins and Scott C. Doney \\ Department of Marine Chemistry and Geochemistry, Woods Hole Oceanographic Institution, Woods Hole, \\ Massachusetts, USA
}

Received 24 April 2003; revised 4 September 2003; accepted 26 September 2003; published 4 December 2003.

[1] We present an extended series of observations and more comprehensive analysis of a tracer-based measure of new production in the Sargasso Sea near Bermuda using the ${ }^{3} \mathrm{He}$ flux gauge technique. The estimated annually averaged nitrate flux of $0.84 \pm 0.26 \mathrm{~mol}$ $\mathrm{m}^{-2} \mathrm{yr}^{-1}$ constitutes only that nitrate physically transported to the euphotic zone, not nitrogen from biological sources (e.g., nitrogen fixation or zooplankton migration). We show that the flux estimate is quantitatively consistent with other observations, including decade timescale evolution of the ${ }^{3} \mathrm{H}+{ }^{3} \mathrm{He}$ inventory in the main thermocline and export production estimates. However, we argue that the flux cannot be supplied in the long term by local diapycnal or isopycnal processes. These considerations lead us to propose a three-dimensional pathway whereby nutrients remineralized within the main thermocline are returned to the seasonally accessible layers within the subtropical gyre. We describe this mechanism, which we call "the nutrient spiral," as a sequence of steps where (1) nutrient-rich thermocline waters are entrained into the Gulf Stream, (2) enhanced diapycnal mixing moves nutrients upward onto lighter densities, (3) detrainment and enhanced isopycnal mixing injects these waters into the seasonally accessible layer of the gyre recirculation region, and (4) the nutrients become available to biota via eddy heaving and wintertime convection. The spiral is closed when nutrients are utilized, exported, and then remineralized within the thermocline. We present evidence regarding the characteristics of the spiral and discuss some implications of its operation within the biogeochemical cycle of the subtropical ocean. INDEX TERMS: 4808 Oceanography: Biological and Chemical: Chemical tracers; 4845 Oceanography: Biological and Chemical: Nutrients and nutrient cycling; 4805 Oceanography: Biological and Chemical: Biogeochemical cycles (1615); 4820 Oceanography: Biological and Chemical: Gases; KEYWORDS: nutrients, productivity, tritium, helium-3

Citation: Jenkins, W. J., and S. C. Doney, The subtropical nutrient spiral, Global Biogeochem. Cycles, 17(4), 1110, doi:10.1029/2003GB002085, 2003.

\section{Introduction}

[2] The oceans constitute the largest pool of relatively available carbon within the biogeosphere and have been implicated in the long-term regulation of atmospheric $\mathrm{CO}_{2}$, which, through its radiative properties, profoundly influences global climate. While the uptake of anthropogenic $\mathrm{CO}_{2}$ is largely believed to occur by the solubility pump [e.g., Wallace, 2001], the importance of the biological pump is that it plays a much longer term role in the regulation of atmospheric $\mathrm{CO}_{2}$ levels and that it will be influenced by climate-induced changes in circulation and stratification [e.g., Sarmiento et al., 1998]. These changes, in turn, will feed back into the climate system through $\mathrm{CO}_{2}$ release or drawdown. Moreover, concomitant ecological shifts in the food web will lead to further changes in oceanic biogeochemical cycles [e.g., Karl, 1999].

[3] Of the global annual net primary production of $\sim 100 \mathrm{Pg} \mathrm{C}$, around half is fixed within the marine biosphere

Copyright 2003 by the American Geophysical Union. 0886-6236/03/2003GB002085\$12.00
[Field et al., 1998]. Since the marine biosphere is only $\sim 5 \mathrm{Pg} \mathrm{C}$, it turns over the equivalent of its mass on approximately monthly timescales. Thus the cycling of carbon within the upper ocean biosphere occurs very rapidly compared with the decade to century timescales most relevant to global climate change. One can therefore argue that this net primary production cycle will not be a ratelimiting process for climate change. New production and export production, on the other hand, are controlled by processes characterized by longer timescales. In particular, the nutrient loop created by fixation, export, sinking, remineralization, and reflux back to the euphotic zone involves portions of the water column whose ventilation, circulation, and mixing occur on annual to decade to century timescales [e.g., Jenkins, 1988a, 1998].

[4] The oligotrophic ocean covers a large fraction of the ocean's surface area [e.g., Berger et al., 1987] and accounts for at least half of marine export production [e.g., Najjar and Keeling, 2000]. However, it appears that we do not as yet have a complete, quantitative, and mechanistic view of the cycling of nutrients within subtropical oligotrophic waters. Although attempts have been made to model 
the flux of nutrients to the oligotrophic euphotic zone [McGillicuddy and Robinson, 1997; McGillicuddy et al., 1998; Oschlies and Garçon, 1998; Oschlies et al., 2000; Williams and Follows, 1998], satisfactory agreement with the numerous estimates based on geochemical tracer techniques has not yet been achieved.

[5] This study is not intended as a comprehensive review of larger-scale, tracer-based estimates of oceanic productivity [see, e.g., Jenkins, 1995; Lipschultz et al., 2002] but rather is an attempt to quantify the physical input of nutrients using the "flux gauge technique" (FGT) and to highlight the implications regarding some of the other geochemical tracer-based estimates at a well-studied site in the oligotrophic North Atlantic. As a consequence of these considerations we propose a mechanism whereby remineralized nutrients are returned from the main thermocline to the seasonal layer of the North Atlantic subtropical gyre and ultimately to the euphotic zone, a pathway that we call "the subtropical nutrient spiral." Aside from this introductory section, this study comprises four parts. In section 2 we outline, refine, and expand on a geochemical estimate of nitrate flux to the euphotic zone near Bermuda based on a 6-year time series of helium isotope measurements in the mixed layer. In section 3 we ask whether the estimated fluxes are consistent with other observations. In section 4 we propose a mechanism (the nutrient spiral) whereby this flux is supported. In section 5 we explore the ramifications of the nutrient spiral, especially in regard to other tracer-based estimates of new and export production in the subtropical gyre.

\section{Flux Gauge Technique: A Measure of New Production}

[6] Estimates of new production based on geochemical tracer mass budgets offer unique advantages over traditional methods. They average over relevant space scale and timescale processes that are both sporadic and patchy. They further have the attraction of not perturbing the systems being studied. On the negative side, such estimates are to some extent model-dependent and integrate over space scales and timescales in a manner characteristic of the particular tracer system used. They can quantify bulk rates but may not differentiate among potential mechanisms.

[7] We present here an approach to determining new production in the Sargasso Sea near Bermuda. We have chosen this locale as a test bed for our understanding of a classic seasonally oligotrophic system because it is a good example of a well-studied site. Moreover, the large-scale gyre circulation is such that the upstream trajectory fortuitously follows closely the zero net air-sea heat flux line (see Figure 1). Thus the kind of water column evolution associated with a strong net positive heat flux as modeled by Federiuk and Price [1984] and Woods and Barkmann [1986] is not in evidence. That is, the water column is in approximate thermal balance. Hence the Bermuda site at first appears suitable to the more or less one-dimensional mass balance considerations generally used.

[8] Our estimate is based on the ${ }^{3} \mathrm{He}$ flux gauge [Jenkins, 1988a]. The FGT exploits the fact that surface waters near

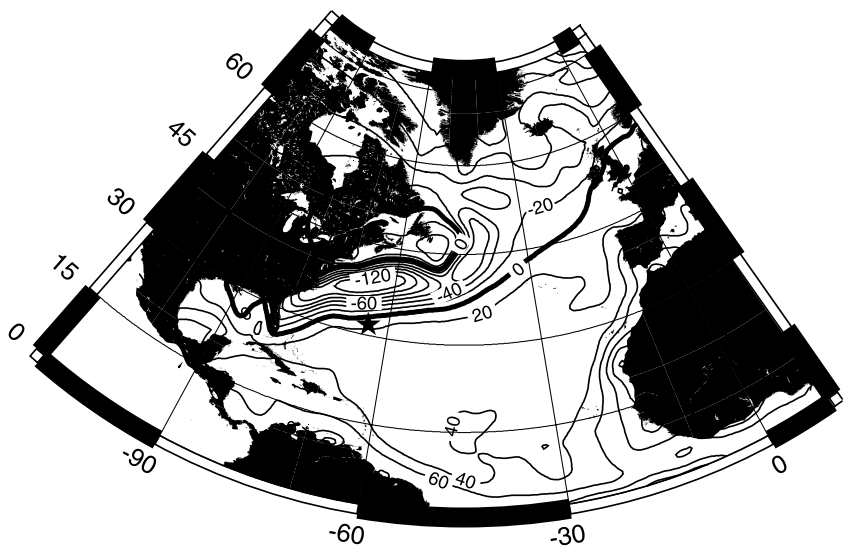

Figure 1. Annual average air-sea heat flux, computed from the Southampton Oceanography Centre climatology [Josey et al., 1999]. The star indicates the Bermuda site.

Bermuda are generally supersaturated in ${ }^{3} \mathrm{He}$. A subsurface, physically mediated flux of this isotope is required to support the air-sea gas exchange flux arising from this excess. Using the subsurface correlation of excess tritiugenic ${ }^{3} \mathrm{He}$ with nutrients leads to an estimate of the corresponding physical supply of nutrients to the euphotic zone. It is a measure of physically mediated new production since it establishes the physical flux of new nutrients (nitrate and phosphate) to the euphotic zone, but it does not include new production arising from biological sources, e.g., from nitrogen fixation. We are implicitly assuming that the processes responsible for transporting ${ }^{3} \mathrm{He}$ to the euphotic zone do not discriminate between ${ }^{3} \mathrm{He}$ and nutrients. Inasmuch as the mechanism must be physical to transport ${ }^{3} \mathrm{He}$ and since numerous studies of large-scale transport of passive tracers within the ocean consistently exhibit no such discrimination, such an assumption is wholly justified.

[9] The original FGT determination was based on a 2-year (1986-1987) time series of helium isotope measurements in the ocean mixed layer near Bermuda [Jenkins, $1988 \mathrm{~b}]$. Here we extend this series to encompass a period of nearly 6 years and perform a more extensive analysis of the results. Figure 2 (top) depicts the mean mixed layer $\delta^{3} \mathrm{He}$, the helium isotope ratio anomaly relative to air, for 35 time series stations. The points represent the mean value for two or more samples measured in the mixed layer, and the error bars represent the statistical uncertainty associated with each determination. The scatter of individual measurements is on average somewhat larger than the analytical errors (the latter being $\sim 0.15 \%$ in $\delta^{3} \mathrm{He}$ ) due to natural variability within the mixed layer.

[10] The solubility equilibrium $\delta^{3} \mathrm{He}$ for water and seawater has been measured with great accuracy in the laboratory [Benson and Krause, 1980] and has an average value of $-1.66 \%$ for the temperature range of interest. However, air-sea gas exchange and bubble trapping are isotopically fractionating and can drive $\delta^{3} \mathrm{He}$ away from this value [Fuchs et al., 1987; Jenkins, 1988b]. The direction and magnitude of this effect are governed by the relative contributions of complete versus partial bubble trapping to 

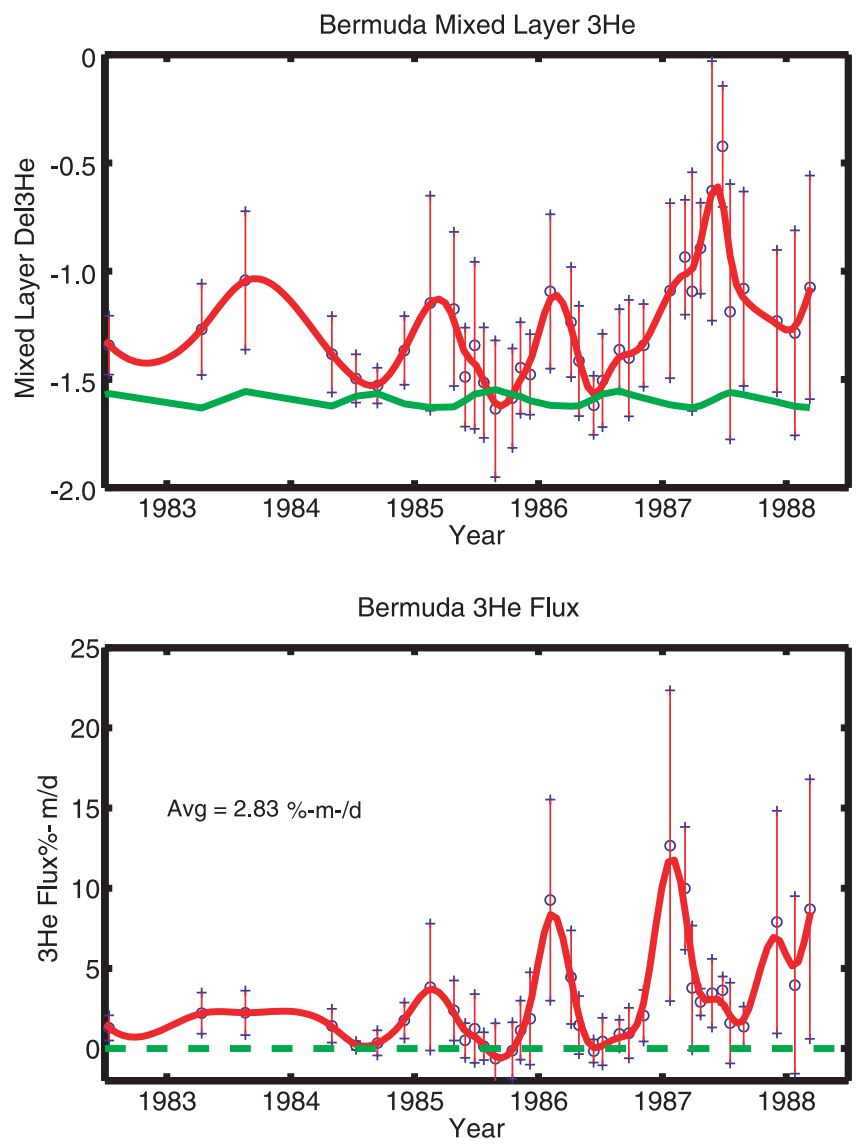

Figure 2. (top) Time series of $\delta^{3} \mathrm{He}$ in the mixed layer near Bermuda and (bottom) the computed ${ }^{3} \mathrm{He}$ sea-air gas flux.

air entrainment. This, in turn, can be sensitively determined by the relative saturation anomalies of $\mathrm{He}(\Delta \mathrm{He})$ and $\mathrm{Ne}$ $(\Delta \mathrm{Ne})$ in near-surface waters, largely because of the similar solubilities but greatly different molecular diffusivities of these two gases [Jenkins, 1988b]. The saturation anomaly is the percentage deviation from solubility equilibrium with air, for example,

$$
\Delta \mathrm{He}=\left(\frac{C(\mathrm{He})}{C^{*}(\mathrm{He})}-1\right) \times 100 \%,
$$

where $C^{*}$ is the solubility equilibrium concentration. Using the correlation between saturation anomalies makes the calculation relatively insensitive to any systematic uncertainties in solubilities of these gases. Consideration of a number (182) of surface water $\mathrm{He}$ and $\mathrm{Ne}$ measurements in the subtropical North Atlantic yields a slope $1.07 \pm 0.03$ in $\Delta \mathrm{Ne}$ versus $\Delta \mathrm{He}$. Comparison of this slope to that generated by a seasonal mixed layer gas exchange model driven by National Centers for Environmental Prediction (NCEP) reanalysis forcing for the period of 1980-1990 that we have run for this purpose yields an estimated fraction of partial (versus complete) bubble trapping of $0.8 \pm 0.1$ (this ratio is slightly higher than previous estimates; see Jenkins [1988b] for a general description of this calculation). Using this proportion, we compute an elevation in the solubility equilibrium $\delta^{3} \mathrm{He}$ of $0.06 \pm 0.02 \%$ for the observed average surface water $\Delta \mathrm{He}$ of $2.6 \%$. This offset is included in the calculation of the baseline $\delta^{3} \mathrm{He}$ depicted by the green line in Figure 2 (top).

[11] In order to compute the air-sea ${ }^{3} \mathrm{He}$ flux we calculate the average gas exchange rate for each ${ }^{3} \mathrm{He}$ determination on the basis of 6-hourly NCEP reanalysis winds near Bermuda for a 2-week period preceding and following each observation using the recently proposed cubic gas exchange-wind speed relationship [Wanninkhof and McGillis, 1999]. Choice of the older quadratic relationship [Wanninkhof, 1992] yields slightly higher but not significantly different results. The resultant ${ }^{3} \mathrm{He}$ fluxes are presented in Figure 2 (bottom) and average to $2.83 \pm$ $0.74 \% \mathrm{~m} \mathrm{~d}^{-1}$. The uncertainty quoted here includes uncertainties in "baseline" $\delta^{3} \mathrm{He}$, an estimated uncertainty of $20 \%$ in the gas exchange rate, and random and systematic uncertainties associated with sampling, mass spectrometric measurement, and standardization.

[12] The record shows two significant features: a seasonal maximum in the winter and a trend to larger fluxes toward the end of the observation period. The former arises from the periodic mining of ${ }^{3} \mathrm{He}$ by deep winter convection, and the longer-term trend is due to deeper winter convection during the latter part of the time series. It must be remembered that the timing of the observed ${ }^{3} \mathrm{He}$ flux on a seasonal timescale is a reflection of the relationship between the mixed layer depth and the wind-driven gas exchange rate rather than the actual transport of ${ }^{3} \mathrm{He}$ (and hence nutrients) to the euphotic zone. That is, the ${ }^{3} \mathrm{He}$ flux to the atmosphere is highest when the mixed layer is deepest, but this ${ }^{3} \mathrm{He}$ may be partly or largely ${ }^{3} \mathrm{He}$ that has accumulated in the euphotic zone throughout the year. Unfortunately, we do not at present have sufficient data to resolve this subsurface seasonal buildup.

[13] The production of ${ }^{3} \mathrm{He}$ by the in situ decay of bomb tritium within the seasonal layer at Bermuda (i.e., 2.5 tritium unit (TU) average concentration over the decade in the upper 250-300 m, which is "accessed" by wintertime convection) amounts to $0.4-0.5 \% \mathrm{~m} \mathrm{~d}^{-1}$, which leaves a residual ${ }^{3} \mathrm{He}$ flux of $2.4 \pm 0.7 \% \mathrm{~m} \mathrm{~d}^{-1}$ that must come from somewhere else. Below the seasonal layer the concentration of tritiugenic ${ }^{3} \mathrm{He}$ increases into the thermocline, reaching a maximum at a depth of $600-700 \mathrm{~m}$. This maximum arises from the accumulation of ${ }^{3} \mathrm{He}$ due to the decay of bomb tritium that has penetrated the thermocline. We argue that the flux of ${ }^{3} \mathrm{He}$ at the sea surface arises from the leakage of this isotope from the thermocline and that in fact this ${ }^{3} \mathrm{He}$ must come from significant depths: The annual integrated gas exchange flux of ${ }^{3} \mathrm{He}$ is equivalent to the average inventory of excess ${ }^{3} \mathrm{He}$ within at least the upper $350-$ $400 \mathrm{~m}$. It is likely that greater depths are involved in the supply of this flux because although there are temporal variations, this inventory does not disappear on an annual basis.

[14] Recognizing that there is a large-scale correlation of ${ }^{3} \mathrm{He}$ with nitrate in the upper thermocline (see Figure 3), we can multiply the ${ }^{3} \mathrm{He}$ flux by the $\mathrm{NO}_{3}:{ }^{3} \mathrm{He}$ ratio to yield an estimate of the corresponding physical nitrate flux to the 
(a)

(c)
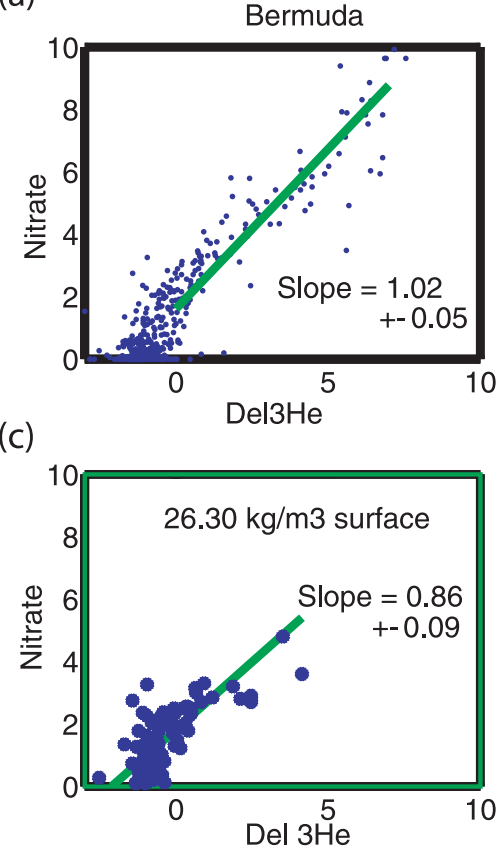

(b)

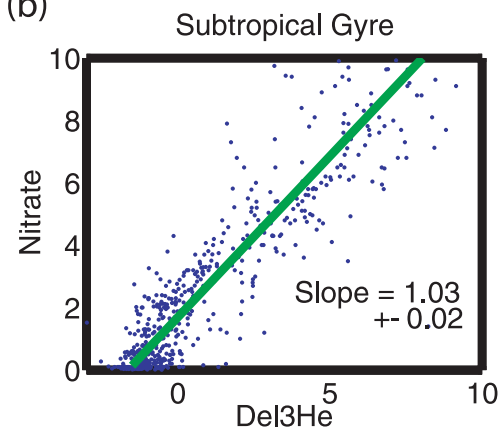

(d)

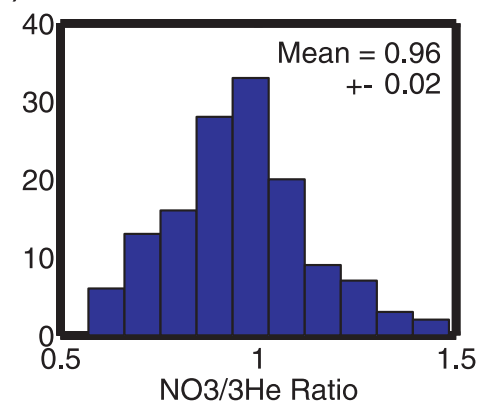

Figure 3. Correlation of nitrate versus $\delta^{3} \mathrm{He}$ in the Sargasso Sea (a) in the water column near Bermuda, (b) throughout the subtropical gyre, and (c) locally on the $26.3 \mathrm{~kg} \mathrm{~m}^{-3}$ isopycnal surface. (d) Distribution of nitrate: ${ }^{3} \mathrm{He}$ ratios in thermocline waters. The slopes and mean value are expressed in units of $\mu$ mol $\mathrm{N} \mathrm{kg}^{-1} \%^{-1}$.

euphotic zone. We can arrive at this ratio in four possible ways: the vertical correlation of $\mathrm{NO}_{3}$ and ${ }^{3} \mathrm{He}$ in the upper thermocline at Bermuda $\left(1.02 \pm 0.05 \mu \mathrm{mol} \mathrm{kg}{ }^{-1} \%^{-1}\right.$, Figure 3a), the bulk correlation of $\mathrm{NO}_{3}$ and ${ }^{3} \mathrm{He}$ within the North Atlantic subtropical gyre thermocline $(1.03 \pm$ $0.02 \mu \mathrm{mol} \mathrm{kg} \%^{-1}$, Figure $\left.3 \mathrm{~b}\right)$, the correlation of ${ }^{3} \mathrm{He}$ and $\mathrm{NO}_{3}$ on a representative isopycnal surface $(0.86 \pm$ $0.09 \mu \mathrm{mol} \mathrm{kg} \%^{-1}$, Figure $3 \mathrm{c}$ ), or the mean $\mathrm{NO}_{3}:{ }^{3} \mathrm{He}$ ratio in Sargasso Sea upper thermocline waters (0.96 \pm $0.02 \mu \mathrm{mol} \mathrm{kg} \%^{-1} \%^{-1}$, Figure $\left.3 \mathrm{~d}\right)$. It appears that regardless of whether we assume that the transport is by diapycnal or isopycnal mixing or by lateral advection, the flux ratio is within errors of the same value: $0.97 \pm 0.06 \mu \mathrm{mol} \mathrm{kg}^{-1} \%-1$. Using this ratio combined with the requisite ${ }^{3} \mathrm{He}$ supply flux, we estimate an annual average nitrate flux to the euphotic zone of $0.84 \pm 0.26 \mathrm{~mol} \mathrm{~m}^{-2} \mathrm{yr}^{-1}$.

\section{Do the Fluxes Make Sense?}

[15] It can be argued that the ${ }^{3} \mathrm{He}$ and nitrate fluxes estimated in section 2, although surprisingly large, are consistent with two other observations. First, the examination of the time evolution of the tritium plus ${ }^{3} \mathrm{He}$ inventory in the upper kilometer in the Sargasso Sea reveals a systematic decrease over the period 1974-1989 equivalent to $220 \pm 14 \mathrm{TU} \mathrm{m} \mathrm{yr}^{-1}$ [Jenkins, 1998], which corresponds to an average loss of $2.7 \pm 0.2 \% \mathrm{~m} \mathrm{~d}^{-1}$ in ${ }^{3} \mathrm{He}$ from the thermocline over that time frame. Thus the euphotic zone flux could be supported by thermocline exhalation of bomb tritiugenic ${ }^{3} \mathrm{He}$. In the absence of any other significant source of this isotope we must conclude that the observed flux of ${ }^{3} \mathrm{He}$ from the ocean surface at Bermuda must ultimately be supplied from the thermocline below. The pathway that this tracer takes is the subject of section 4.

[16] The second corroboration of this flux involves estimates of export production in the Sargasso Sea. It can be expected on the basis of mass balance arguments that on annual and longer timescales, export and new production should be closely matched. Estimates of export production at Bermuda have been made on the basis of seasonal oxygen cycling [Jenkins and Goldman, 1985] and aphotic zone oxygen utilization rates [Jenkins and Wallace, 1992]. Numerical integration of these aphotic zone oxygen consumption rates as a function of depth (between 100 and $2800 \mathrm{~m}$ ) yields a net water column oxygen demand of $7.1 \pm 1.4 \mathrm{~mol} \mathrm{~m}^{-2} \mathrm{yr}^{-1}$. Using the Redfield stoichiometry of $-\Delta \mathrm{O}_{2}: \mathrm{NO}_{3}=10.6 \pm 0.9$ [Anderson and Sarmiento, 1994] or $-\Delta \mathrm{O}_{2}: \mathrm{N}=9.1 \pm 0.5$ [Hedges et al., 2002] would require a nitrate flux of $0.67 \pm 0.14$ or $0.78 \pm$ $0.15 \mathrm{~mol} \mathrm{~N} \mathrm{~m} \mathrm{yr}^{-1}$, respectively. These export fluxes include a small contribution due to nitrogen fixation, which amounts to $\sim 0.07 \mathrm{~mol} \mathrm{~N} \mathrm{~m} \mathrm{yr}^{-1}$ [Gruber and Sarmiento, 1997], so the nitrate fluxes are reduced to $0.60 \pm 0.14$ or $0.71 \pm 0.15 \mathrm{~mol} \mathrm{~N} \mathrm{~m}^{-2} \mathrm{yr}^{-1}$, respectively. Both numbers are within errors of our FGT estimate.

[17] Thus, although the FGT estimate of nitrate flux seems large, there are two independent observations that yield consistent results. The unresolved question is by what pathway do the ${ }^{3} \mathrm{He}$ and nutrients arrive at the Sargasso Sea surface? The pathway must be physical since the FGT, 
based on an inert gas isotope, "sees" only physical transport processes.

\section{Nutrient Spiral}

[18] We first explore and reject possible pathways for these fluxes. If the fluxes were supplied by diapycnal mixing, an extraordinarily large turbulent mixing coefficient (order $10^{-3} \mathrm{~m}^{2} \mathrm{~s}^{-1}$, obtained by dividing the observed vertical gradient in either tracer by the flux) would be needed [Jenkins, 1988b]. While such mixing rates are possible within or near the ocean surface layer, the requirement that the nutrients must come from at least the top of the main thermocline means that this requirement would be directly at variance with our knowledge of thermocline mixing rates, which are about 2 orders of magnitude lower [Garrett, 1979; Jenkins, 1980; Ledwell et al., 1993; Rooth and Ostlund, 1972]. Moreover, such a large mixing rate would do violence to upper ocean heat budgets. We have confirmed this by using a one-dimensional upper ocean model driven by 6-hourly NCEP reanalysis surface fields to simulate the seasonal cycle at Bermuda. Although the model adequately mimics the seasonal temperature and density structure over long periods, the model-simulated upward flux of ${ }^{3} \mathrm{He}$ from the thermocline is more than a factor of 20 too small. Increasing the ${ }^{3} \mathrm{He}$ flux can be achieved by raising the vertical mixing rate in the model, but even a modest change in mixing rate results in grossly unrealistic thermal and mixed layer depth behavior. The fact that such simple models, which apparently work so well in the upper ocean, might fail to explain the transport of materials through their lower boundaries is not unexpected [Large et al., 1994] and is a reflection of the fact that they are missing vital three-dimensional physics.

[19] The heat flux conflict could be mitigated by arguing that the transport of nutrients and ${ }^{3} \mathrm{He}$ occurs along isopycnal surfaces, which tend to be approximately isothermal. However, isopycnal mixing cannot directly supply the observed flux, either. The lateral distribution of ${ }^{3} \mathrm{He}$ on the $26.4 \mathrm{~kg} \mathrm{~m}^{-3}$ isopycnal surface, the wintertime outcrop in the Sargasso Sea in the vicinity of Bermuda, exhibited a positive curvature of $1.6 \pm 0.4 \times 10^{-12} \% \mathrm{~m}^{-2}$ in the $1980 \mathrm{~s}$. Combined with an estimated isopycnal mixing rate of $1.8 \times$ $10^{3} \mathrm{~m}^{2} \mathrm{~s}^{-1}$ [e.g., Jenkins, 1991], this leads to a ${ }^{3} \mathrm{He}$ flux convergence of $0.05 \% \mathrm{~m} \mathrm{~d}^{-1}$ over the upper $200 \mathrm{~m}$ of the water column, about a factor of 40 too low. It is conceivable that somewhat larger mixing coefficients could be argued for in the western part of the gyre but clearly are not high enough to support the required flux.

[20] Other processes can be considered. Convergence of nutrients in the Ekman layer can result in modest fluxes near the gyre boundaries [Williams and Follows, 1998], but they fall far short of requirements in the interior. McGillicuddy and Robinson [1997] and McGillicuddy et al. [1998] have proposed an "eddy rectification" model whereby the uplift of nutrient-rich waters into the euphotic zone followed by a rapid utilization and subsequent lowering of nutrient-poor waters results in a net upward flux of nutrients. Calculations using a $0.1^{\circ}$ resolution basin model achieve a flux that approaches what is required [McGillicuddy et al., 2003], but the calculations to date are incomplete in that they rely on an artificial nutrient-restoring term at depth to support the flux. The recharging of nutrients in the deeper layers depleted by the eddy-heaving mechanism must occur horizontally for reasons discussed at the beginning of this section. If isopycnal mixing were the only mechanism involved in recharge, this requires unrealistically high isopycnal mixing rates. Eddy rectification increases the depth over which ${ }^{3} \mathrm{He}$ and nutrients can be mined from the upper thermocline but does not fully relieve the local vertical flux problem because even this enhanced depth does not have sufficient local radioactive decay and remineralization rates to support the required ${ }^{3} \mathrm{He}$ and nutrient fluxes, respectively.

[21] Moreover, it is unclear how such models will manage the ${ }^{3} \mathrm{He}$ flux, which differs from nutrients in a crucial way near the ocean surface layer: While nutrients are "taken up" in the model on arrival in the euphotic layer, ${ }^{3} \mathrm{He}$ must be lost by gas exchange from the mixed layer. This is evident in the "kink" in the ${ }^{3} \mathrm{He}: \mathrm{NO}_{3}$ relationship at low nutrient levels (i.e., near the surface) seen in Figure 3a. A flux of ${ }^{3} \mathrm{He}$ by the eddy-heaving mechanism ultimately requires diabatic processes to connect the "heaved layer" to the mixed layer. Evidence of a sea surface temperature signature associated with mesoscale eddies in the Sargasso Sea [Glover et al., 2002; McGillicuddy et al., 2001; McGillicuddy et al., 2003] indicates that water parcels are reaching the surface mixing layer, so this connection may indeed occur. However, further observations and numerical experimentation are required to explore the hypothesis.

[22] In summary, although the accumulation of nutrients within the thermocline due to remineralization fluxes must ultimately be balanced in the steady state by a corresponding back flux to the surface ocean, it is clear that local diapycnal or isopycnal exchange cannot support the bulk of this flux. Therefore we must turn to lateral advection. Building on ideas and observations by Pelegri and Csanady [1991, 1994] and Pelegri et al. [1996], we postulate that the shallow nutrient cycle of the North Atlantic subtropical gyre is dominated by a so-called nutrient spiral, which can be characterized in the following manner (see Figure 4): (1) Waters subducted into the main thermocline experience a buildup of nutrients at depth from the remineralization of export production within the gyre. (2) These waters are entrained into the Gulf Stream/western boundary current system [Pelegri and Csanady, 1991; Pelegri et al., 1996]. (3) There, enhanced diapycnal mixing [Pelegri and Csanady, 1994] repartitions a fraction of these nutrients onto density horizons that effectively mix and detrain [Young, 1984] into the gyre interior via the recirculation. (4) The nutrients become accessible to biota via wintertime convection into the seasonal layer and eddyheaving processes [e.g., see McGillicuddy et al., 1998].

[23] We can ask whether this hypothetical pathway makes quantitative sense in the following manner. The Gulf Stream has been shown to transport a total of $\sim 300 \mathrm{kmol} \mathrm{s}^{-1}$ nitrate at $24^{\circ} \mathrm{N}$ latitude [Pelegri and Csanady, 1991]. About a quarter of this transport $\left(\sim 50 \mathrm{kmol} \mathrm{s}^{-1}\right)$ occurs on isopycnals with density less than 26.5 and more than $25.6 \mathrm{~kg} \mathrm{~m}^{-3}$. At $36^{\circ} \mathrm{N}$ the total nitrate transport increases to $>850 \mathrm{kmol} \mathrm{s}^{-1}$, with a transport in excess of $100 \mathrm{kmol} \mathrm{s}^{-1}$ occurring on the 


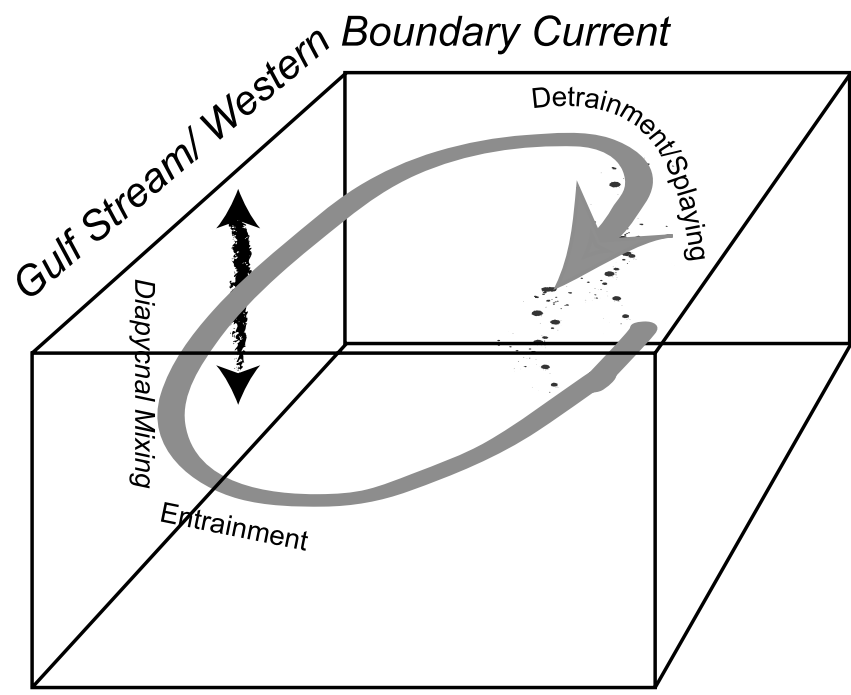

Figure 4. Schematic of the subtropical nutrient spiral, showing the entrainment of nutrient-rich thermocline waters into the Gulf Stream/western boundary current system, diapycnal mixing of nutrients onto lighter isopycnals, and detrainment and splaying into the seasonally accessible layer within the Sargasso Sea.

density range of interest [Pelegri and Csanady, 1991]. This nutrient transport convergence occurs in response to entrainment of nutrient-rich thermocline waters into the Gulf Stream [Pelegri and Csanady, 1991]. In the regions of high current shear (low Richardson number flow) and sharpened spatial gradients of the Gulf Stream, diapycnal mixing becomes large and important, fluxing nutrients between density classes and in particular from the nutrient-bearing thermocline waters to lighter density horizons [Pelegri and Csanady, 1994]. On the basis of data available at this time it is unclear what fraction of the nutrient flux convergence on the lighter isopycnals occurs as a result of diapycnal mixing versus horizontal convergence.

[24] Downstream and eastward from $36^{\circ} \mathrm{N}$ (as far east as $35^{\circ} \mathrm{W}$ ) the total nutrient transport in the Gulf Stream decreases by $>450 \mathrm{kmol} \mathrm{s}^{-1}$, while the transport within the lighter isopycnals decreases by $\sim 100 \mathrm{kmol} \mathrm{s}^{-1}$ over a distance of $\sim 3000 \mathrm{~km}$ [Pelegri et al., 1996]. This results in an advective flux divergence of 0.15 and $0.033 \mathrm{~mol} \mathrm{~m}^{-1} \mathrm{~s}^{-1}$ for the total and "seasonal layer" isopycnals, respectively. The divergence is caused in large part by the detrainment of water from the boundary current and the splaying of streamlines associated with recirculation within the Sargasso Sea gyre, which can prove an effective mechanism for amplification of isopycnal mixing effects [Young, 1984]. If this advective flux divergence of nitrate were spread over a band $1000 \mathrm{~km}$ wide (i.e., the approximate latitudinal extent of the recirculation region of the Sargasso Sea), it would amount to an area mean nitrate injection into the thermocline of order $3.7 \mathrm{~mol} \mathrm{~m}^{-2} \mathrm{yr}^{-1}$ (the deeper recirculation) and a net flux to the seasonal layer of $\sim 1 \mathrm{~mol} \mathrm{~m}^{-2} \mathrm{yr}^{-1}$. Since the bulk of the transport divergence of the Gulf Stream can be traced to a southward turn into the recirculation [Worthington, 1976], it seems probable that the bulk of this divergence flows into the Sargasso Sea mode water formation regions and the rest of the gyre's seasonal layer.

[25] We can estimate this "detrainment flux" in the following way. The distribution of ${ }^{3} \mathrm{He}$ on the $26.3 \mathrm{~kg} \mathrm{~m}^{-3}$ surface exhibits a slope of $2.1 \pm 0.4 \times 10^{-6} \% \mathrm{~m}^{-1}$ oriented with the decreasing direction to the southeast. The general flow in the upper layers near Bermuda is from the northeast with a mean speed of $\sim 6.5 \times 10^{-2} \mathrm{~m} \mathrm{~s}^{-1}$ in the warm water layers (estimated from the warm water transport charts of Worthington [1976, Figure 41, p. 93]). Integrated over the seasonal layer near Bermuda (the upper $250 \mathrm{~m}$ ), this results in a ${ }^{3} \mathrm{He}$ advective flux divergence of $3.0 \pm 0.6 \% \mathrm{~m} \mathrm{~d}^{-1}$, a value clearly sufficient to support the observed mixed layer ${ }^{3} \mathrm{He}$ flux. Inasmuch as the $\mathrm{NO}_{3}:{ }^{3} \mathrm{He}$ ratio is uniform within the gyre (see Figure 3), the above calculation means that the implied nitrate flux can also be supported by this mechanism. While admittedly crude, these calculations show that advective flux divergence within the Gulf Stream can readily support the fluxes required by the FGT observations and implied by the thermocline tritium $-{ }^{3} \mathrm{He}$ evolution and export production estimates.

\section{Character and Implications of the Nutrient Spiral}

[26] The schematic circulation we envision here is a gyrescale upward spiral of thermocline remineralized nutrients, a fraction of which returns to advect around through the gyre within the main thermocline but a portion of which moves into the subtropical gyre seasonal layer to become available to the biota either directly within the euphotic zone or ultimately by winter convection or eddy heaving. The "pitch" of this spiral (i.e., the inverse of the average number of times a parcel of thermocline water circulates around the gyre before eventually mixing up to the seasonal layer) is linked in a crude way to the inverse of the effective Peclet number of these tracers within the thermocline. Examination of the North Atlantic thermocline tritium- ${ }^{3} \mathrm{He}$ relationship [Jenkins, 1988b; Young, 1984] suggests that this number is of order 1, thanks to strong mixing associated with the boundary current. This is supported by additional observations: (1) Surface water of the North Atlantic subtropical gyre reached a peak tritium concentration of $\sim 18$ TU [Dreisigacker and Roether, 1978]. (2) If a parcel of water subducted into the thermocline were to retain its identity over the subsequent 2 decades (between the mid1960s and mid-1980s), it would have a tritium concentration of $\sim 6 \mathrm{TU}$ and a ${ }^{3} \mathrm{He}$ concentration of $\sim 12 \mathrm{TU}$. (3) The largest concentration of ${ }^{3} \mathrm{He}$ observed within the subtropical gyre in the mid-1980s (based on thousands of observations) is 3TU [Jenkins, 1988b]. These observations support the idea that thermocline water subducted within the subtropical gyre is effectively mixed (i.e., the strongly diffusive limit in Young's terminology [Young, 1984]) and outgassed on decade timescales (i.e., that the pitch of the subtropical nutrient spiral is order 1).

[27] The nutrient spiral that we describe here is distinct from the schematic "figure eight" circuit recently suggested by Williams and Follows [2003]. In that instance, they argue 
for a downward nutrient spiral within the subtropical gyre (driven by downward Ekman pumping and remineralization) that couples to an upward spiral within the northern subpolar gyre (driven by upward Ekman pumping and deep winter convection). While such a process may in some way contribute to the net upward transport of remineralized nutrients, it seems to us that such a multistep process will be impeded by the requirement that the nutrient flux would have to cross the intergyre boundary twice. Moreover, both net air-sea heat flux and biological fixation processes within the subpolar gyre tend to move nutrients onto deeper isopycnals.

[28] The subtropical nutrient spiral thus appears to be a candidate mechanism for supplying nutrients (and ${ }^{3} \mathrm{He}$ ) to those layers within the subtropical gyre that are accessed by wintertime convection and eddy heaving. That is, we argue that this three-dimensional gyre-scale transport is the pathway whereby the seasonal layer nutrients and ${ }^{3} \mathrm{He}$ are restored at some shallow depth in order to sustain the observed upward fluxes to the euphotic zone on annual and longer timescales. Therefore this mechanism would effectively control and regulate new production within the subtropical gyre on decade timescales.

[29] There is also an interesting implication regarding euphotic zone mass budgets that is related to the stoichiometry of new production and export remineralization. Since the proposed transport mechanism is purely advective/diffusive, passive tracers will be carried in their "source proportions" so that the arriving nutrients will be accompanied by corresponding amounts of oxygen debt (AOU) and remineralized excess dissolved inorganic carbon (DIC). Elemental ratios associated with the two processes are the same to a crude approximation [Laws, 1991], so the new production stimulated by the arrival of these nutrients to the euphotic zone will produce just enough oxygen to cancel the oxygen debt and draw down enough inorganic carbon to negate the DIC excess. Since the timescale associated with nutrient uptake in the euphotic zone (normally a few days) is much less than for air-sea exchange of oxygen ( $\sim 1$ month) and $\mathrm{CO}_{2}(\sim 1$ year $)$, it seems unlikely that an associated oxygen debt or DIC excess could be "neutralized" prior to nutrient utilization. In other words, the impact of the nutrient spiral on new production may be more or less invisible from the viewpoint of euphotic zone oxygen and carbon budgets.

[30] Similar arguments may be applied to the eddyheaving mechanism proposed by McGillicuddy and Robinson [1997] in that nutrients raised from depths to the euphotic zone will have accompanying oxygen debt and excess DIC, which will approximately negate the resultant photosynthetic signature. What happens in practice, however, may be carbon fixation and remineralization (and oxygen production and consumption) in substantially "non-Redfield" ratios and possibly nonlocal biological transport. Figure 5 shows a sequence of profiles taken near Bermuda in mid-1986 during the passage of a mode water eddy. Note that the arrival of the mode water eddy (the red points and lines in Figure 5) is characterized by shoaling of the $19^{\circ} \mathrm{C}$ isotherm underlain by a much thicker mode water layer. At the base of the euphotic zone (between 50 and $100 \mathrm{~m}$ depth) we see elevated concentrations of ${ }^{3} \mathrm{He}$, nitrate,

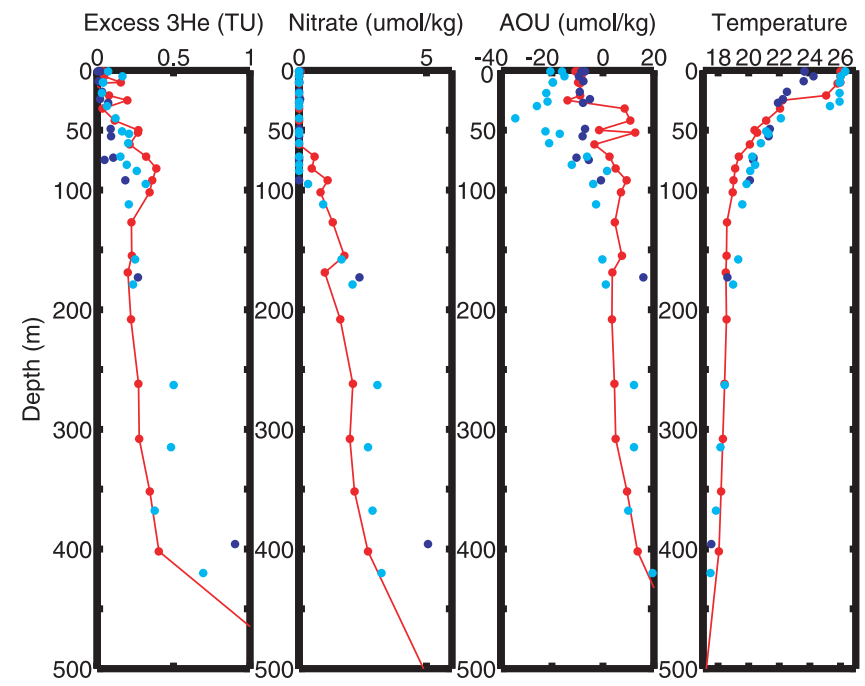

Figure 5. Profiles of excess ${ }^{3} \mathrm{He}$ (in tritium units (TU)), nitrate (in $\mu \mathrm{mol} \mathrm{kg}{ }^{-1}$ ), oxygen debt (AOU) (in $\mu \mathrm{mol} \mathrm{kg}{ }^{-1}$ ), and temperature (in ${ }^{\circ} \mathrm{C}$ ) for a sequence of stations near Bermuda in the spring and summer of 1986 . The red points correspond to the passage of a mode water eddy, and the blue and cyan points correspond to the preceding and following stations, respectively.

and AOU compared with preceding stations (the blue points). The lower euphotic zone of the subsequent station (the cyan points in Figure 5), however, is characterized by zero nitrate, a smaller residual excess ${ }^{3} \mathrm{He}$ signature, and a pronounced oxygen excess (negative AOU). The first two features are characteristic of the difference in boundary conditions between these two tracers: Nitrate is consumed within the euphotic zone, whereas ${ }^{3} \mathrm{He}$ is lost only from the mixed layer. The accumulation of excess oxygen must arise from a substantial deviation from the Redfield stoichiometry or biologically mediated transport. Curiously, however, the AOU minimum (i.e., oxygen anomaly maximum) is most pronounced at $\sim 50 \mathrm{~m}$, which is above where the nutrient injection appears most strongly.

[31] These substantial deviations from the Redfield stoichiometry can be used to explain the existence of the pronounced summertime euphotic zone cycles discussed and modeled by many researchers [Bates et al., 1996; Craig and Hayward, 1987; Emerson et al., 1995; Gruber et al., 1998; Jenkins and Goldman, 1985; Michaels et al., 1994; Shulenberger and Reid, 1981; Spitzer and Jenkins, 1989], but these features may be a more modest signal driven by the anomalous stoichiometry of a possibly larger material turnover. Moreover, the strong horizontal flux divergence observed at the tip of the spiral calls into question the fundamentally one-dimensional character of those calculations. The kind of carbon cycle imbalance described by Michaels et al. [1994] still remains an unresolved puzzle and may, in fact, be exacerbated by the additional lateral fluxes implied by the FGT measurements and the nutrient spiral. The lateral advective flux convergence of DIC implied by the ${ }^{3} \mathrm{He}$ and nitrate calculations that we have 
done here suggests an awkward perturbation to the carbon budget that Michaels et al. [1994] attempt to close. If we assume Redfield stoichiometry [Anderson and Sarmiento, 1994] holds, there would be a lateral flux convergence exceeding $7 \mathrm{~mol} \mathrm{~m}^{-2} \mathrm{yr}^{-1}$ for excess DIC, substantially distorting the budget calculations of Michaels et al. [1994].

[32] A final point of concern involves the question of the extent of the physical domain inherent in the new and export production calculations. By definition, the FGT and nutrient spiral calculations performed here draw the boundary for "new" nutrients at the base of the seasonal layer $(\sim 250 \mathrm{~m})$. These calculations do not account for those nutrients that may be rapidly remineralized in the $\sim 150 \mathrm{~m}$ water column that spans the area between the base of the euphotic zone and the base of the seasonal layer. In contrast, estimates of export production based on the vertical integration of aphotic zone oxygen utilization rates include this layer. Moreover, oxygen utilization rates are highest in this zone, so the distinction would seem critically important. However, it should be borne in mind that the oxygen utilization rates based on transient tracer invasion calculations are characterized by multiyear to decade timescales, and hence any remineralization, reflux, and fixation occurring on seasonal timescales would be "invisible" in the budget. That is, the intensive recycling of nutrients in the seasonally convected aphotic zone would not appear in the export production estimate. Put another way, one can think in terms of two "new production" loops, one long-term loop (the nutrient spiral) dominated by the large-scale circulation of the gyre and characterized by Redfield stoichiometry, and another shortterm seasonal loop (within the seasonal layer) characterized by non-Redfield stoichiometry driven by extreme oligotrophy and rapid shallow remineralization [Anderson and Pondhaven, 2003]. Indeed, the vertical structure of $\mathrm{C}: \mathrm{N}$ ratios reflects the imprint of the latter, showing substantial deviations down to the base of the seasonal layer.

[33] In summary, we have described an important and perhaps dominant pathway whereby inorganic nutrients that are remineralized within the main thermocline are returned to the ocean surface. The mechanics of this process clearly differ from the local one-dimensional exchange budgets traditionally used. This has significant implications regarding how one would model the biological response of the subtropical ocean gyres to changes in climatic forcing. Rather than responding in a simple way to changes in vertical stratification [e.g., see Gnanadesikan et al., 2002; Sarmiento et al., 1998], the efficiency of the biological pump may be directly controlled by processes such as westward intensification, buoyancy flux, and wind stress [e.g., Luyten and Stommel, 1986].

[34] Acknowledgments. The authors thank numerous colleagues for discussions on the BATS data and Sargasso Sea, including in particular D. McGillicuddy, plus valuable comments from anonymous reviewers. This work was supported by grants from the National Science Foundation (OCE-0221247) and NSF/ONR NOPP (N000140210370). This is Woods Hole Oceanographic Institution contribution 11017.

\section{References}

Anderson, L. A., and J. L. Sarmiento, Redfield ratios of remineralization determined by nutrient data-analysis, Global Biogeochem. Cycles, 8, 65$80,1994$.
Anderson, T. R., and P. Pondhaven, Non-Redfield carbon and nitrogen cycling in the Sargasso Sea: Pelagic imbalances and export flux, Deep Sea Res., Part I, 50, 573-591, 2003.

Bates, N. R., A. F. Michaels, and A. H. Knap, Seasonal and interannual variability of oceanic carbon dioxide species at the U.S. JGOFS Bermuda Atlantic Time-Series Study (BATS) site, Deep Sea Res., Part II, 43, $347-$ 384, 1996.

Benson, B. B., and D. Krause Jr., Isotopic fractionation of helium during solution: A probe for the liquid state, J. Solution Chem., 9, 895-909, 1980.

Berger, W. H., K. H. Fischer, C. Lai, and G. Wu, Ocean productivity and organic carbon flux. part 1: Overview and maps of primary production and export production, SIO Ref. 87-30, 67 pp., Scripps Inst. Oceanogr., San Diego, Calif., 1987.

Craig, H., and T. Hayward, Oxygen supersaturation in the ocean: Biological versus physical contributions, Science, 235, 199-202, 1987.

Dreisigacker, E., and W. Roether, Tritium and ${ }^{90} \mathrm{Sr}$ in North Atlantic surface water, Earth Planet. Sci. Lett., 38, 301-312, 1978.

Emerson, S., P. Quay, C. Stump, D. Wilbur, and R. Schudlich, Chemical tracers of productivity and respiration in the subtropical Pacific Ocean, J. Geophys. Res., 100, 15,873-15,887, 1995.

Federiuk, J. M., and J. F. Price, Subduction mechanisms in the eastern North Atlantic (abstract), Eos Trans AGU, 65, 943, 1984.

Field, C. B., M. J. Behrenfeld, J. T. Randerson, and P. G. Falkowski, Primary production of the biosphere: Integrating terrestrial and oceanic components, Science, 281, 237-240, 1998.

Fuchs, G., W. Roether, and P. Schlosser, Excess ${ }^{3} \mathrm{He}$ in the ocean surface layer, J. Geophys. Res., 92, 6559-6568, 1987.

Garrett, C., Mixing in the ocean interior, Dyn. Atmos. Oceans, 3, 239-265, 1979.

Glover, D. M., S. C. Doney, A. J. Mariano, R. H. Evans, and S. J. McCue, Mesoscale variability in time series data: Satellite-based estimates for the U.S. JGOFS Bermuda Atlantic Time-Series Study (BATS) site, J. Geophys. Res., 107(C8), 3092, doi:10.109/2000JC000589, 2002.

Gnanadesikan, A., R. D. Slater, N. Gruber, and J. L. Sarmiento, Oceanic vertical exchange and new production: A comparison between models and observations, Deep Sea Res., Part II, 49, 363-401, 2002.

Gruber, N., and J. L. Sarmiento, Global patterns of marine nitrogen fixation and denitrification, Global Biogeochem. Cycles, 11, 235-266, 1997.

Gruber, N., C. D. Keeling, and T. F. Stocker, Carbon-13 constraints on the seasonal inorganic carbon budget at the BATS site in the northwestern Sargasso Sea, Deep Sea Res., Part I, 45, 673-717, 1998.

Hedges, J. I., J. A. Baldock, Y. Gelinas, C. Lee, M. L. Peterson, and S. G. Wakeham, The biochemical and elemental compositions of marine plankton: A NMR perspective, Mar. Chem., 78, 47-63, 2002.

Jenkins, W. J., Tritium and ${ }^{3} \mathrm{He}$ in the Sargasso Sea, J. Mar. Res., 38, $533-$ $569,1980$.

Jenkins, W. J., Nitrate flux into the euphotic zone near Bermuda, Nature, $331,521-523,1988$ a.

Jenkins, W. J., Using anthropogenic tritium and ${ }^{3} \mathrm{He}$ to study subtropical gyre ventilation and circulation, Philos. Trans. R. Soc. London, Ser. A, 325, 43-61, 1988b.

Jenkins, W. J., Determination of isopycnal diffusivity in the Sargasso Sea, J. Phys. Oceanogr., 21, 1058-1061, 1991.

Jenkins, W. J., Tracer based inferences of new and export primary productivity in the oceans, U.S. Natl. Rep. Int. Union Geod. Geophys. $1991-$ 1994, Rev. Geophys., 33, 1263-1269, 1995.

Jenkins, W. J., Studying thermocline ventilation and circulation using tritium and ${ }^{3} \mathrm{He}$, J. Geophys. Res., 103, 15,817-15,831, 1998.

Jenkins, W. J., and J. C. Goldman, Seasonal oxygen cycling and primary production in the Sargasso Sea, J. Mar. Res., 43, 465-491, 1985.

Jenkins, W. J., and D. W. R. Wallace, Tracer based inferences of new primary production in the sea, in Primary Production and Biogeochemical Cycles in the Sea, edited by P. G. Falkowski and A. D. Woodhead, pp. 299-316, Plenum, New York, 1992.

Josey, S., E. Kent, and P. Taylor, New insights into the ocean heat budget closure problem from analysis of the SOC air-sea flux climatology, J. Clim., 12(9), 2856-2880, 1999.

Karl, D., A sea of change: Biogeochemical variability in the North Pacific subtropical gyre, Ecosystems, 2, 181-214, 1999.

Large, W. G., J. C. McWilliams, and S. C. Doney, Oceanic vertical mixing: A review and a model with nonlocal boundary layer parameterization, Rev. Geophys., 32, 363-403, 1994.

Laws, E. A., Photosynthetic quotients, new production and net community production in the open ocean, Deep Sea Res., Part A, 38, 143-167, 1991.

Ledwell, J. R., A. J. Watson, and C. S. Law, Evidence for slow mixing rates across the pycnocline from an open-ocean tracer-release experiment, Nature, 364, 701-703, 1993. 
Lipschultz, F., N. R. Bates, C. A. Carlson, and D. A. Hansell, New production in the Sargasso Sea: History and current status, Global Biogeochem Cycles, 16(1), 1001, doi:10.1029/2000GB001319, 2002.

Luyten, J. R., and H. Stommel, Gyres driven by combined wind and buoyancy flux, J. Phys. Oceanogr., 16, 1551-1560, 1986.

McGillicuddy, D. J., Jr., and A. R. Robinson, Eddy-induced nutrient supply and new production in the Sargasso Sea, Deep Sea Res., Part I, 44, $1427-1450,1997$.

McGillicuddy, D. J., Jr., A. R. Robinson, D. A. Seigel, H. W. Jannasch, D. Johnson, T. D. Dickey, J. McNeil, A. F. Michaels, and A. H. Knap, Influence of mesoscale eddies on new production in the Sargasso Sea, Nature, 394, 263-268, 1998.

McGillicuddy, D., V. K. Kosnyrev, J. P. Ryan, and J. A. Yoder, Covariation of mesoscale ocean color and sea-surface temperature patterns in the Sargasso Sea, Deep Sea Res., Part II, 48, 1823-1836, 2001

McGillicuddy, D. J., Jr., L. A. Anderson, S. C. Doney, and M. E. Maltrud, Eddy-driven sources and sinks of nutrients in the upper ocean: Results from a $0.1^{\circ}$ resolution model of the North Atlantic, Global Biogeochem. Cycles, 17(2), 1035, doi:10.1029/2002GB001987, 2003.

Michaels, A. F., N. R. Bates, K. O. Buesseller, C. A. Carlson, and A. H. Knap, Carbon-cycle imbalances in the Sargasso Sea, Nature, 372, 537 $540,1994$.

Najjar, R. G., and C. D. Keeling, Mean annual cycle of air-sea oxygen flux: A global view, Global Biogeochem. Cycles, 14, 573-584, 2000.

Oschlies, A., and V. Garçon, Eddy-induced enhancement of primary production in a model of the North Atlantic Ocean, Nature, 394, 266-268, 1998.

Oschlies, A., W. Koeve, and V. Garçon, An eddy-permitting coupled physical-biological model of the North Atlantic: 2. Ecosystem dynamics and comparison with satellite and JGOFS local studies data, Global Biogeochem. Cycles, 14, 499-523, 2000.

Pelegri, J. L., and G. T. Csanady, Nutrient transport and mixing in the Gulf Stream, J. Geophys. Res., 96, 2577-2583, 1991.

Pelegri, J. L., and G. T. Csanady, Diapycnal mixing in western boundary currents, J. Geophys. Res., 99, 18,275-18,304, 1994.

Pelegri, J. L., G. T. Csanady, and A. Martins, The North Atlantic nutrient stream, J. Oceanogr., 52, 275-299, 1996.

Rooth, C. G., and H. G. Ostlund, Penetration of tritium into the North Atlantic thermocline, Deep Sea Res., 19, 481-492, 1972.
Sarmiento, J. L., T. M. C. Hughes, R. J. Stouffer, and S. Manabe, Simulated response of the ocean carbon cycle to anthropogenic climate warming, Nature, 393, 245-249, 1998

Shulenberger, E., and J. L. Reid, The Pacific shallow oxygen maximum, deep chlorophyll maximum, and primary production reconsidered, Deep Sea Res., Part A, 28, 901-919, 1981.

Spitzer, W. S., and W. J. Jenkins, Rates of vertical mixing, gas exchange and new production: Estimates from seasonal gas cycles in the upper ocean near Bermuda, J. Mar. Res., 47, 169-196, 1989.

Wallace, D. W. R., Storage and transport of excess $\mathrm{CO}_{2}$ in the oceans: The JGOFS/WOCE global $\mathrm{CO}_{2}$ survey, in Ocean Circulation and Climate. Observering and Modelling the Global Ocean, edited by G. Seidler, J. Church, and J. Gould, pp. 489-521, Academic, San Diego, Calif., 2001

Wanninkhof, R., Relationship between wind speed and gas exchange over the ocean, J. Geophys. Res., 97, 7373-7382, 1992.

Wanninkhof, R., and W. R. McGillis, A cubic relationship between air-sea $\mathrm{CO}_{2}$ exchange and wind speed, Geophys. Res. Lett., 26, 1889-1892, 1999.

Williams, R. G., and M. J. Follows, The Ekman transfer of nutrients and maintenance of new production over the North Atlantic, Deep Sea Res. Part I, 45, 461-489, 1998.

Williams, R., and M. J. Follows, Physical transport of nutrients and maintenance of biological production, in Ocean Biogeochemistry: The Role of the Ocean Carbon Cycle in Global Change, edited by M. J. R. Fasham, pp. 19-51, Springer-Verlag, New York, 2003.

Woods, J. D., and W. Barkmann, A Lagrangian mixed layer model of Atlantic $18^{\circ} \mathrm{C}$ water formation, Nature, 319, 574-576, 1986.

Worthington, L. V., On the North Atlantic Circulation, 110 pp., Johns Hopkins Univ. Press, Baltimore, Md., 1976.

Young, W. R., The role of western boundary layers in gyre-scale ocean mixing, J. Phys. Oceanogr., 14, 478-483, 1984.

S. C. Doney and W. J. Jenkins, Department of Marine Chemistry and Geochemistry, Woods Hole Oceanographic Institution, Bigelow 2096MS11, Woods Hole, MA 02543, USA. (sdoney@whoi.edu; wjenkins@ whoi.edu) 